\title{
The use of agitated saline in a patient with unroofed coronary sinus
}

\author{
Salim Yasar ${ }^{\text {a }}$, Suat Gormel ${ }^{\text {b }}$, Erkan Yildirim ${ }^{c}$, Murat Celik ${ }^{c, *}$, Uygar Cagdas Yuksel $^{\text {c }}$ \\ ${ }^{a}$ Etimesgut Military Hospital, Service of Cardiology, Ankara, Turkey \\ b Beytepe Military Hospital, Service of Cardiology, Ankara, Turkey \\ c Gulhane Military Medical Faculty, Department of Cardiology, Ankara, Turkey
}

\section{A R T I C L E I N F O}

\section{Article history:}

Received 19 June 2016

Received in revised form 4 September 2016

Accepted 5 September 2016

Available online 21 September 2016

\section{Keywords:}

Unroofed coronary sinus

Echocardiography

Agitated saline

Negative contrast effect

\begin{abstract}
A B S T R A C T
Although it is difficult to diagnose with transthoracic echocardiography, a negative right atrial echo-contrast effect might be an indicator of unroofed coronary sinus in patients with dilated right heart chambers and without obvious atrial and/or ventricular septal defect.

(C) 2016 The Society of Cardiovascular Academy. Production and hosting by Elsevier B.V. This is an open access article under the CC BY-NC-ND license (http://creativecommons.org/licenses/by-nc-nd/4.0/).
\end{abstract}

\section{Introduction}

Unroofed coronary sinus (UCS) is an infrequent congenital cardiac anomaly, Partial or complete deficiency of the roof of the coronary sinus might result in a communication between right and left atriums. It is usually associated with persistent left sided superior vena cava (LSVC), which is the most common anomaly of systemic venous drainage, and other forms of complex congenital heart disease, typically heterotaxy syndromes. ${ }^{1}$

Although imaging techniques plays a fundamental role in the diagnosis of UCS, it might be difficult to diagnose with transthoracic echocardiography, because of its limited ability in evaluation of posterior structures of the heart. Transesophageal echocardiography and cardiac MRI can evaluate more properly posterior cardiac structures. Nonetheless, computed tomography (CT) can more accurately assess the posterior structures of the heart and can be useful to identify the UCS due to its excellent spatial resolution. ${ }^{2}$ We herein report a case of a patient with unroofed coronary sinus.

\section{Case report}

A 21-year old man presented to our cardiology clinic with a shortness of breath and mild exercise intolerance. His past medical history was unremarkable. His physical examination was within normal limits and

\footnotetext{
is Peer review under responsibility of The Society of Cardiovascular Academy.

* Corresponding author at: Department of Cardiology, Gulhane Military Medical Academy, 06018 Etlik-Ankara, Turkey.

E-mail address: drcelik00@hotmail.com (M. Celik).

Peer review under responsibility of The Society of Cardiovascular Academy.
}

12-lead surface ECG was normal. Transthoracic echocardiography showed dilated right heart chambers, mildly dilated pulmonary artery, pulmonary artery systolic pressure of $45 \mathrm{mmHg}$, and Qp/Qs ratio was more than 1.5. However, we did not observe any defect on IAS or IVS. Afterwards, we performed an agitated saline study via patient's left antecubital vein, and bubbles were not seen in the coronary sinus or the left cardiac chambers, and persistent left sided superior vena cava (LSVC) was excluded. Interestingly, during agitated saline study, we detected a negative right atrial echo contrast effect as an indicator of left-to-right shunt. To confirm the diagnosis, we performed a transesophageal echocardiography. Nevertheless, we could not find any abnormality that may cause cardiac enlargement and all pulmonary veins were drained normally. Again, we observed a negative right atrial echo contrast effect, even though we did not show any ASD, VSD or abnormal pulmonary venous drainage (Fig. $1 \mathrm{~A}$ ). We suspected that the patient would be UCS. Afterwards, a multi detector CT (MDCT) was performed and revealed an abnormal communication between the base of the left atrium and the roof of the coronary sinus, consistent with an UCS (Fig. 1B). There was no suggestion of persistent LSVC. Initially, the patient's symptoms were not severe and he was managed conservatively and periodically echocardiographic screening was recommended. However, the patient reported that the complaint of shortness of breath was increased 's complaints was increased compared to 3 months ago. Therefore, the patient referred to surgery and UCS was corrected by minimal-invasive cardiac surgery. At 3-month follow-up, his complaints were totally resolved.

\section{Discussion}

UCS is the uncommon type of atrial septal defect. The UCS is classified into 4 groups: type 1, completely UCS with persistent LSVC; type 



Fig. 1. Transthoracic Echocardiography; “*” shows a negative right atrial echo contrast effect (A), Sagittal oblique reformatted image demonstrates the unroofing of the coronary sinus (B).
2, completely UCS without persistent LSVC; type 3, partially unroofed mid portion; and type 4, partially unroofed terminal portion. Our case seems to be consistent with type 2 . Although it might be difficult to diagnose with transthoracic echocardiography, a negative right atrial echo-contrast effect might be an indicator of UCS in patients with dilated right heart chambers and without obvious ASD or VSD on transthoracic and/or transesophageal echocardiography.

Generally clinical presentation depends on the size of the defect and the degree of left to right shunt. The spectrum of symptoms may range from asymptomatic nonspecific complaints to severe dyspnea due to overt right-sided heart failure from chronic right ventricular volume overload. Nonetheless, UCS diagnosis should be thought during the evaluation of an unknown cardiac murmur, right-sided heart enlargement, transient cyanosis or hypoxia, or paradoxical embolism. ${ }^{3}$ Management depends on the clinical symptoms, which are related to the size of the defect, and the severity of the inter-atrial shunt, and surgical intervention would be considered if the symptoms couldn't be improved medically.

\section{Conflict of interest}

None.

\section{References}

1. Ramos N, Fernandez-Pineda L, Tamariz-Martel A, Villagra F, Egurbide N, Maitre MJ. Absent right superior vena cava with left superior vena cava draining to an unroofed coronary sinus. Rev Esp Cardiol 2005;58(8):984-987.

2. Thangaroopan M, Truong QA, Kalra MK, Yared K, Abbara S. Images in cardiovascular medicine. Rare case of an unroofed coronary sinus: diagnosis by multidetector computed tomography. Circulation 2009;119(16):e518-e520.

3. Ootaki Y, Yamaguchi M, Yoshimura N, Oka S, Yoshida M, Hasegawa T. Unroofed coronary sinus syndrome: diagnosis, classification, and surgical treatment. J Thorac Cardiovasc Surg 2003;126(5):1655-1656. 